\title{
Optimizing Pelvic X-Ray indication in blunt trauma patients using clinical criteria
}

\section{Uso de critérios clínicos para a otimização da indicação de radiografia simples de pelve das vítimas de trauma fechado}

Júlio Patrocínio Moraes ${ }^{1}$; José Gustavo Parreira, TCBC-SP2,3; Pedro de Souza lucarelli-Antunes (iD); Giovanna Zucchini Rondini²; Jacqueline Arantes Gianninni Perlingeiro 2,3 ; Jose Cesar Assef, TCBC-SP2,3.

\begin{abstract}
A B S T R A C T
Objective: to identify a subgroup of blunt trauma patients with very low chance of sustaining pelvic fractures based on clinical criteria. Methods: retrospective analysis of the trauma registry data, collected in a period of 24 months. We selected adult blunt trauma patients who had a PXR on admission. The frequency of pelvic fractures was calculated for the following groups: Normal neurological examination at admission (NNE), hemodynamical stability (HS), normal pelvic examination at admission (NPE), less than 60 years old (ID<60) and absence of distracting injuries (ADI). Logistic regression analysis was carried out in order to create a probability model of negative PXR. Results: an abnormal PXR was identified in 101 (3.3\%) out of the 3,055 patients who had undergone a PXR at admission. Out of these, 1,863 sustained a NNE, with 38 positive CXRs $(2.0 \%)$ in this group. Considering only the 1,535 patients with NNE and HS, we found 28 positive PXRs (1.8\%). Out of these, 1,506 have NPE, with 21 abnormal PXRs (1.4\%). Of these, 1,202 were younger than $60 \mathrm{y}$, with 11 positive PXRs $(0.9 \%)$. By adding all these criteria to the $A D I$, we found 2 abnormal PXRs in $502(0.4 \%)$ cases. The probability model including all these variables had a 0,89 area under the ROC curve. Conclusions: by adding clinical criteria, it is possible to identify a group of trauma patients with very low chance of sustaining pelvic fractures. The necessity of PXR in these patients needs to be reassessed.
\end{abstract}

Keywords: Contusions. Pelvis. Radiography. Diagnostic Imaging. Quality of Health Care.

\section{INTRODUCTION}

A round $3 \%$ of all bone fractures are in the pelvis ${ }^{1}$. Of the victims of blunt trauma admitted to hospitals, $9.3 \%$ have pelvic fractures ${ }^{2}$. The lethality of traumatized with pelvic fractures is estimated between $10 \%$ and $16 \%$, and in the $2-4 \%$ of patients with open fractures, mortality can reach up to $3045 \%^{1-4}$. The frequency of associated injuries can reach $90 \%$ of cases, influencing prognosis 5,6 . This means that pelvic fractures are an indicator of potential lethality, which justifies their prompt identification ${ }^{7-9}$.

The guidelines of the Advanced Trauma Life Support (ATLS) recommend that the simple radiography of the anteroposterior pelvis be performed systematically on victims of severe blunt trauma upon admission to the trauma room ${ }^{10}$. The advantage of such conduct would be precisely the early identification of patients who need some form of hemostasis, such as external fracture fixation, extra-peritoneal pelvic tamponade and/or embolization by angiography ${ }^{11-15}$. Early diagnosis would decrease time to treatment and blood loss, which is essential for a better prognosis.

However, taking into account the total number of blunt trauma victims in major trauma centers, the number of normal radiographs of the pelvis is significant. Even when there is a fracture, in $22 \%$ of these cases the diagnosis is only possible through computed tomography ${ }^{16}$. Negative tests generate costs and increase the length of stay in the emergency services, which can worsen the patient's clinical prognosis and interfere with the patient's care flow. Importantly, in many cases of

1 - Irmandade da Santa Casa de Misericórdia de São Paulo, Departamento de Cirurgia - São Paulo - SP - Brasil 2 - Faculdade de Ciências Médicas da Santa Casa de São Paulo, Disciplina de Cirurgia - São Paulo - SP - Brasil 3 - Irmandade da Santa Casa de Misericórdia de São Paulo, Serviço de Emergência - São Paulo - SP - Brasil 
high-energy trauma there is indication of abdominal and pelvic computed tomography, which would put in doubt the need for prior pelvis radiography ${ }^{17,18}$.

Currently, several authors have questioned the mandatory simple radiographic examination of the pelvis in the Emergency Room. However, the criteria for patient selection are not clear in the literature. Apparently, this test would be reserved mainly for hemodynamically unstable victims of high-energy trauma ${ }^{12,13,15}$.

The aim of the present study is to identify, through the evaluation of clinical criteria, a group of victims of blunt trauma in whom the frequency of pelvic fractures is minimal.

\section{METHODS}

This project was approved by the Ethics in Research Committee of the Brotherhood of Santa Casa de Misericórdia de São Paulo (CAAE 60936616.0.0000.5479). We carried out a retrospective analysis of the information contained in the Trauma Registry of the Emergency Service of the Santa Casa de São Paulo. We included adult victims of blunt trauma, seen between 2006 and 2008, with complete information in the records and submitted to pelvic anteroposterior radiography at admission. We evaluated demographic data, trauma mechanism, vital signs at admission, trauma indices, complementary exams, associated diseases, diagnosed injuries, and treatment.

Pelvic X-Rays (PXR) were performed in an anteroposterior view and interpreted by the most senior resident (surgeon / orthopedist) in conjunction with the attending physician on duty (surgeon). Exams were characterized as positive or negative for the presence of a pelvic fracture. We did not consider findings unrelated to the traumatic event and / or previous illnesses.

We established the following clinical variables, obtained at the patient's initial assessment:

1. Normal neurological examination at admission (NNE): patient alert and responsive, without motor or sensory alteration, with Glasgow coma scale equal to 15 and without factors that hampered the examination, such as the use of sedatives or drugs;

2. Hemodynamic stability (HS): patient with heart rate below $100 \mathrm{bpm}$ and systolic blood pressure above $100 \mathrm{mmHg}$;

3. Normal Pelvis Examination at admission (NPE): patient without pain on palpation or instability on pelvic examination;

4. Age below 60 years $(A G E<60)$;

5. Absence of distracting injuries (ADI): Abbreviated Injury Scale (AIS) $>2$ in other body segments.

We compared the frequency of pelvic fractures between patients with and without the analyzed variables, using the Chi-square test and considering $p$ $<0.05$ as significant. We calculated the Odds Ratio and the $95 \%$ confidence interval for the absence of pelvic fractures according to the clinical variables.

From the variables, we progressively overlapped the clinical criteria, with the objective of identifying a group whose probability of presenting abnormal PXR at admission was the lowest possible. The variables were also included in the logistic regression using the Enter method, with the goal of building a predictive model of "absence" of pelvic fractures. We calculated the area under the Receiver Operating Characteristic (ROC) curve to estimate the accuracy of the model produced in the logistic regression. We used the Statystical Package for Social Sciences (SPSS) software version 21.0 for statistical analysis, considering $\mathrm{p}<0.05$ as significant.

\section{RESULTS}

In the period, 3,055 adult victims of blunt trauma underwent pelvis radiography, constituting the study group. Of those, 101 patients (3.3\%) had fractures of the pelvis identified at the admission X-Ray.

Of the 101 patients with fractures of the pelvis, $75(74.2 \%)$ were male. The age varied between 14 and 87 years (mean $41.6 \pm 19.4$ years) and 16 patients (15.8\%) were older than 60 years. The most frequent trauma mechanisms were run over (50 cases $-49.5 \%$ ) and falls from a height ( 28 cases $-27.7 \%$ ). Twenty-eight of the 101 patients with pelvic fractures had altered pelvic 
physical examination at admission (27.7\%). The means and standard deviations for systolic blood pressure (SBP), Glasgow coma scale, and respiratory rate at admission were $109.5 \pm 45.0 \mathrm{mmHg}, 12.0 \pm 4.4$, and $18.4 \pm 4.8$ bpm, respectively. SBP was below $100 \mathrm{mmHg}$ in 32 cases (31.7\%). Lesions with AIS greater than 2 were identified in the cephalic, thoracic, abdominal and extremity segments in $31(30.7 \%), 34(33.7 \%), 39(38.6 \%)$, and $86(85,1 \%)$ patients, respectively. Pelvic fractures were considered unstable in 32 cases (31.7\%) (Table 1).

In the analysis of 1,863 patients with NNE, we identified 39 altered PXRs (2.1\%). In the 1,535 subjects with NNE and HS, we observed 28 altered PXRs $(1.8 \%)$. In the 1,506 ones with NNE, HS, and NPE, we identified 21 with positive PXRs (1.4\%). Of the 1,202 cases with NNE, HS, NPE, and $A G E<60,11$ had altered PXRs (0.9\%). Finally, of the 502 individuals with NNE, $H S, N P E, A G E<60$, and $A D I$, there were only 2 abnormal PXRs (0.4\%) (Table 2).

Pelvic fractures were significantly less frequent among patients with NNE $(2.1 \%$ vs. $5.8 \%, p<0.001$, OR 2.87 [95\% Cl 1.914 .31$]$ ), HS (2.1\% vs. 9.9\%, p $<0.001$, OR 5.22 [95\% Cl 3.477 .86$])$, NPE (2.5\% vs. $61.4 \%, p<0.001$, OR 62.19 [95\% Cl 32.51 118.97]), and $\mathrm{ADI}(0.9 \%$ vs. $10.7 \%, \mathrm{p}<0.001$, OR $12.92[95 \%$ Cl 7.93 21.04]) (Figure 1). The logistic regression model using the Enter method and including the variables NNE, $H S, N P E, A G E<60$ and $A D I$ showed an area under the ROC curve (AUC) of 0.89 (Table 3 and Figure 2 ).

\section{DISCUSSION}

Pelvic fractures can be considered as a marker of severe trauma ${ }^{8,19}$. The simple diagnosis of a pelvic fracture should alert the surgeon to the greater probability of retroperitoneal hemorrhage or even associated injuries that may require specific treatment ${ }^{20}$. In our study, we observed severe injuries (AIS > 2) in the skull, thorax, abdomen and extremities, respectively in 30.7\%, 33.7\%, $38.6 \%$, and $85.1 \%$. About $10 \%$ of patients were admitted with hemodynamic instability and $30 \%$ of the fractures were considered mechanically unstable. Thus, the rapid identification of a fractured pelvis is a priority in the care of victims of blunt trauma.

Some current guidelines recommend liberal criteria for the realization of simple pelvis radiography at admission 10,12,14. Recently, the real need for this practice has been questioned, as a large number of these tests are normal ${ }^{20-23}$. The best selection of patients to perform PXR would increase accuracy, reducing costs and exposure to radiation $18,22,24$. However, there is no consensus on the best form of selection.

Table 1. General analysis of 101 patients with fractures of the pelvis. (SBP: Systemic Blood Pressure; GCS: Glasgow Coma Scale; AIS: Abbreviated Injury Scale).

\begin{tabular}{lc}
\hline Variable & Cases (\%) \\
Male patient & $75(74.2 \%)$ \\
Age $>60$ yo & $16(15.8 \%)$ \\
SBP $<100 \mathrm{mmHg}$ & $32(31.7 \%)$ \\
GCS $<9$ & $24(23.8 \%)$ \\
Run over mechanism & $50(49.5 \%)$ \\
Fall from height & $28(27.7 \%)$ \\
Altered pelvic physical & $28(27.7 \%)$ \\
examination & $31(30.7 \%)$ \\
AIS $>2$ cephalic segment & $34(33.7 \%)$ \\
AIS $>2$ thoracic segment & $39(38.6 \%)$ \\
AIS $>2$ abdominal segment & $86(85.1 \%)$ \\
AIS>2 extremity segment & $32(31.7 \%)$ \\
Unstable pelvic fracture &
\end{tabular}

Table 2. Frequency of pelvic fractures according to overlapping clinical criteria. (NNE: Normal Neurological Examination; HS: Hemodynamic Stability; NPE: Normal Pelvis Examination; AGE: Age; ADI: Absence of Distracting Injuries).

\begin{tabular}{lcc}
\hline Clinical criteria & $\begin{array}{c}\text { Total } \\
\text { cases }\end{array}$ & $\begin{array}{c}\text { Cases (\%) } \\
\text { with altered } \\
\text { Pelvic XR }\end{array}$ \\
\hline $\begin{array}{l}\text { Patients who underwent } \\
\text { pelvis radiography }\end{array}$ & 3055 & $101(3.3 \%)$ \\
NNE & 1863 & $39(2.0 \%)$ \\
HS & 2336 & $47(2.0 \%)$ \\
NPE & 3011 & $74(2.4 \%)$ \\
AGE $>60$ & 2350 & $76(3.2 \%)$ \\
ADI & 2630 & $39(1.5 \%)$ \\
NNE + HS & 1535 & $28(1.8 \%)$ \\
NNE + HS + NPE & 1506 & $21(1.4 \%)$ \\
NNE + HS + NPE + AGE<60 & 1202 & $11(0.9 \%)$ \\
NNE + HS + NPE + AGE $<60$ & 502 & $2(0.4 \%)$ \\
+ ADI & & \\
\hline
\end{tabular}


Table 3. Logistic regression using the Enter method with the variables assessed in the study (NNE: Normal Neurological Examination; HS: Hemodynamic Stability; NPE: Examination of the Normal Pelvis; AGE: Age; ADI: Absence of Distracting Injuries).

95\% C.I.for

$\operatorname{EXP}(B)$

\begin{tabular}{lrrrrrrrr} 
& B & \$.E. & Wald & df & Sig. & Exp(B) & Lower & Upper \\
\hline Step 1 ${ }^{\text {a ExNNL(1) }}$ &,- 521 &, 271 & 3,699 & 1 &, 054 &, 594 &, 349 & 1,010 \\
EH(1) &,- 882 &, 265 & 11,056 & 1 &, 001 &, 414 &, 246 &, 696 \\
ID60(1) &,- 658 &, 336 & 3,833 & 1 &, 050 &, 518 &, 268 & 1,001 \\
ALD_SemAISEx t(1) & $-2,821$ &, 369 & 58,331 & 1 &, 000 &, 060 &, 029 &, 123 \\
ExPelveNL(1) & $-4,924$ &, 518 & 90,473 & 1 &, 000 &, 007 &, 003 &, 020 \\
Constant & 5,886 &, 370 & 252,837 & 1 &, 000 & 360,039 & & \\
\hline
\end{tabular}

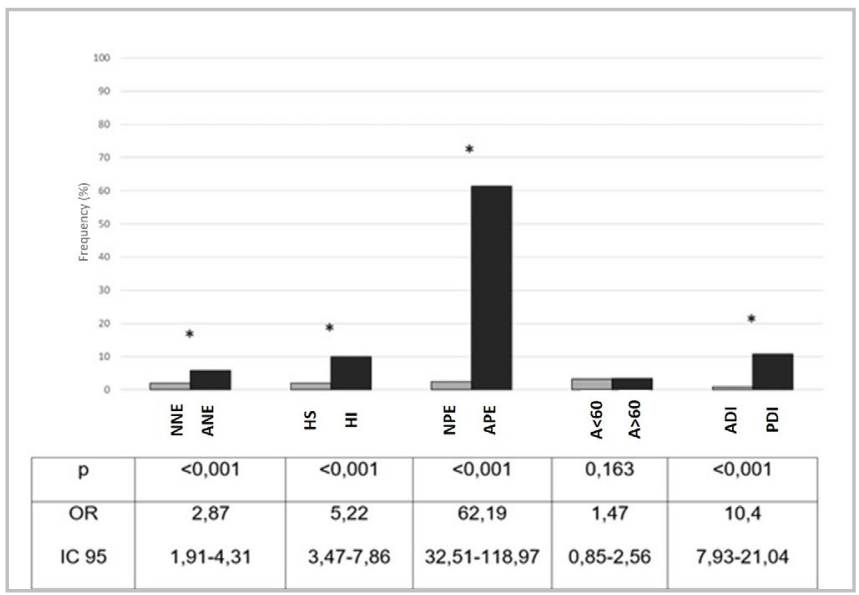

Figure 1. Comparison of pelvic fracture frequency within the subgroups of patients with and without the studied variables. NNE: Normal Neurological Examination; ANE: Altered Neurological Examination; HS: Hemodynamic stability; HI: Hemodynamic instability; NPE: Normal Pelvis Examination; APE: Altered Pelvis Examination; $A G E<60$ : Up to 59 years; $A G E>$ 60: Over 60 years; ADI: Absence of Distracting Injuries; PDI: Presence of Distracting Injuries, with AIS $>2 ;{ }^{*} p<0.001$.

In our study, 3.3\% of blunt trauma victims had fractures at the pelvic X-Ray. However, approximately two thirds of the patients with fractures had a normal pelvic physical examination at admission. Therefore, we understand that the selection to perform PXR must also take into account other criteria besides the physical exam. We analyzed other variables readily available for the initial evaluation, in addition to the pelvic examination, such as age, hemodynamic stability, neurological examination, and the presence of distracting injuries.

We should note that the physical examination can only be considered reliable when there is no altered level of consciousness, hence the importance of a normal

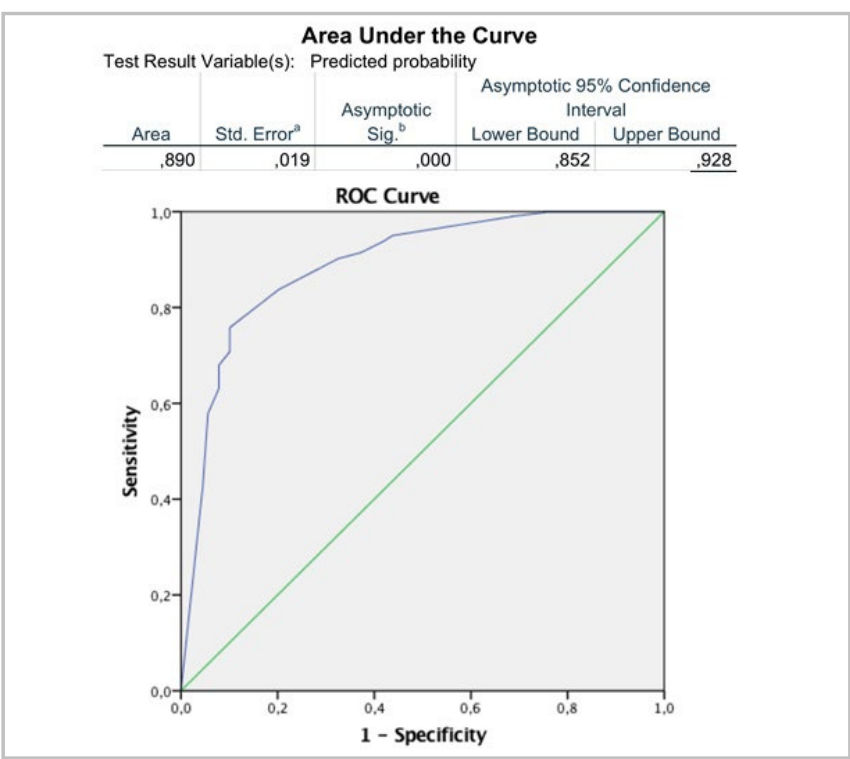

Figure 2. ROC curve and Area under the curve (AUC) of the predictive model that included all the studied variables.

neurological examination. Likewise, distracting injuries can take the patient's attention away, masking possible pelvic lesions. For this reason, we chose to define such injuries as those with AIS $>2$ (severe).

With the overlap of these variables, we could identify a group of patients with less than $0.5 \%$ probability of presenting fractures of the pelvis. When uniting the variables age less than 60 years, hemodynamic stability, normal neurological examination, absence of distracting lesions, and normal pelvis examination, the frequency of abnormal radiographs was $0.4 \%$. This way, the association of the multiple proposed clinical variables would reduce the number of radiographs by $16.4 \%$, 
consequently reducing costs and time of care.

In 2013, Paydar et al. analyzed 1,679 victims of high-energy blunt trauma ${ }^{24}$. Of these, 389 had hemodynamic stability and normal pelvic physical examination, of whom only one $(0.25 \%)$ had an abnormal pelvic radiograph. These authors concluded that the simple radiograph of the pelvis could be removed from the initial screening protocols of high-energy blunt trauma patients who had hemodynamic stability and normal pelvis examination. Our study added other variables to this theory, further reducing the incidence of pelvic fractures in the clinical decision.

One can question the sensitivity of the pelvis radiography to identify minor fractures. In 2006, Obaid et al. demonstrated that in $51 \%$ of patients with pelvic fractures the diagnosis was not possible with a simple pelvic radiograph, but by computed tomography ${ }^{25}$. This group proposes that there is no need to perform PXR in patients who will undergo CT scans. Other studies had similar findings ${ }^{16-18,21}$. This fact calls for well-established criteria to be used in the indication of imaging exams, in the pursuit of unidentified fractures and unnecessary exams.

In 2009, Dechert et al. evaluated elderly patients (age $>65$ years) with pelvic fractures and found that this group has a longer hospital stay and a worse evolution when compared with younger individuals, with increased mortality (20.4\%) and higher risk of death due to multiple organ failure ${ }^{26}$. In our sample, $15.8 \%$ of patients with abnormal pelvic radiography were older than 60 years. It is noteworthy that there was no statistical difference between the groups over the age of 60 and under it regarding the frequencies of pelvic fractures. Although the elderly have greater skeletal fragility, the mechanisms of trauma are different. However, in patients over 60 years of age, performing PXR is more advocated, as the diagnosis can be more difficult, worsening prognosis.

The final message of the present study is that it is possible, with the use of clinical criteria, to identify a group of victims of blunt trauma with minimal probability of presenting pelvic fractures. These data support the selective indication of PXR in such cases, based on the proposed clinical criteria.

\title{
R E S U M O
}

\begin{abstract}
Objetivo: identificar, baseados em critérios clínicos, grupo de vítimas de trauma fechado com baixa probabilidade de apresentar fraturas na radiografia simples de pelve à admissão (RXP). Método: análise retrospectiva dos dados de registro de trauma em um período de 24 meses. Foram selecionados adultos vítimas de trauma fechado que realizaram RXP à admissão. A frequência de fraturas de pelve foi calculada nos seguintes grupos: exame neurológico normal à admissão (ExNN), estabilidade hemodinâmica (EH), exame da pelve normal à admissão (ExPN), idade inferior a 60 anos $(I D<60)$ e ausência de lesões distrativas (ALD). Estas variáveis foram sobrepostas, na tentativa de identificar um grupo com a menor frequência de fraturas de pelve. Por meio de regressão logística, foi criado modelo preditivo de "ausência" de fraturas de pelve. Resultados: foram identificados 101 (3,3\%) RXP positivos dentre os 3.055 realizados. Nos 1.863 pacientes com ExNN, identificamos 39 RXP alteradas (2,1\%). Nos 1.535 com ExNN e EH, observaram-se 28 RXP alteradas (1,8\%). Nos $1.506 \mathrm{com}$ EXNN, EH e EXPN, identificamos 21 com RXP positiva (1,4\%). Dos 1.202 com ExNN, EH, EXPN e ID<60, 11 tinham RXP alteradas (0,9\%). Dos 502 com EXNN, EH, EXPN, ID<60 e ALD, houve apenas 2 RXP anormais (0,4\%). $O$ modelo preditivo derivado da regressão logística, apresentou área sob a curva ROC (AUC) de 0,89. Conclusões: $E$ possível identificar grupo vítimas de trauma fechado com probabilidade muito baixa de apresentar fraturas pélvicas com base em critérios clínicos. $A$ necessidade de RXP neste grupo deve ser revista.
\end{abstract}

Palavras chave: Contusões. Pelve. Radiografia. Diagnóstico por Imagem. Qualidade da Assistência à Saúde.

\section{REFERENCES}

1. Grotz MRW, Allami MK, Harwood P, Pape HC, Krettek C, Giannoudis PV. Open pelvic fractures: Epidemiology, current concepts of management and outcome. Injury. 2005;36(1):1-13.

2. Demetriades D, Karaiskakis M, Toutouzas K, Alo K, Velmahos G, Chan L. Pelvic fractures: Epidemiology and predictors of associated abdominal injuries and outcomes. J Am Coll Surg. 2002;195(1):1-10.

3. Yoshihara H, Yoneoka D. Demographic epidemiology of unstable pelvic fracture in the United States from 2000 to 2009: Trends and in-hospital mortality. J Trauma Acute Care Surg. 2014;76(2):380-5.

4. Leone A, Cassar-Pullicino VN, Pérez MH, Guglielmi G. Emergency and Trauma of the Pelvic Ring. Semin 
Musculoskelet Radiol. 2017;21(3):210-7.

5. Farrath S, Parreira JG, Perlingeiro JAG, Solda SC, Assef JC. Fatores preditivos de lesões abdominais em vítimas de trauma fechado. Rev Col Bras Cir. 2012;39(4):295-301.

6. Cannada LK, Taylor RM, Reddix R, Mullis B, Moghadamian E, Erickson M. The Jones-Powell Classification of open pelvic fractures: a multicenter study evaluating mortality rates. J Trauma Acute Care Surg. 2013;74(3):901-6.

7. Costantini TW, Coimbra R, Holcomb JB, Podbielski JM, Catalano R, Blackburn A, et al. Current management of hemorrhage from severe pelvic fractures: Results of an American Association for the Surgery of Trauma multi-institutional trial. J Trauma Acute Care Surg. 2016;80(5):717-25.

8. Li Q, Dong J, Yang Y, Wang G, Wang Y, Liu P, et al. Retroperitoneal packing or angioembolization for haemorrhage control of pelvic fractures - Quasirandomized clinical trial of 56 haemodynamically unstable patients with Injury Severity Score $\geq 33$. Injury. 2016;47(2):395-401.

9. Burlew CC, Moore EE, Stahel PF, Geddes $A E$, Wagenaar AE, Pieracci FM, et al. Preperitoneal pelvic packing reduces mortality in patients with life-threatening hemorrhage due to unstable pelvic fractures. J Trauma Acute Care Surg. 2017;82(2):23342.

10. American College of Surgeons. The Committee on Trauma. ATLS® Advanced Trauma Life Suport@. 8th ed. Chicago (IL): American College of Surgeons; 2018.

11. Costantini TW, Coimbra R, Holcomb JB, Podbielski JM, Catalano RD, Blackburn A, et al. Pelvic fracture pattern predicts the need for hemorrhage control intervention-Results of an AAST multi-institutional study. J Trauma Acute Care Surg. 2017;82(6):10308.

12. Coccolini F, Stahel PF, Montori G, Biffl W, Horer TM, Catena F, et al. Pelvic trauma: WSES classification and guidelines. World J Emerg Surg. 2017;12(5):1-18.

13. Rudloff MI, Triantafillou KM. Management of Pelvic Ring Injuries in Unstable Patients. Orthop Clin North Am. 2016;47(3):551-63.

14. Halawi MJ. Pelvic ring injuries: Emergency assessment and management. J Clin Orthop Trauma. 2015;6(4):252-8.

15. Verbeek DO, Burges AR. Importance of pelvic radiography for initial trauma assessment: an orthopedic perspective. J Emerg Med.2016;50(6):8528.

16. Soto JR, Zhou C, Hu D, Arazoza AC, Dunn E, Sladek P. Skip and save: utility of pelvic $x$-rays in the initial evaluation of blunt trauma patients. Am J Surg. 2015;210(6):1076-9.

17. Vugt VR, Keus F, Kool D, Deunk J, Edwards M. Selective computed tomography $(\mathrm{CT})$ versus routine thoracoabdominal CT for high-energy blunttrauma patients. Cochrane Database Syst Rev. 2013;(12):CD009743.

18. Kim PK. Radiology for Trauma and the General Surgeon. Surg Clin North Am. 2017;97(5):1175-83.

19. Cordts Filho RM, Parreira JG, Perlingeiro JA, Soldá SC, Campos Td, Assef JC. Pelvic fractures as a marker of injury severity in trauma patients. Rev Col Bras Cir. 2011;38(5):310-6.

20. Fu CY, Teng LH, Liao CH, Hsu YP, Wang SY, Kuo LW, et al. The Diminishing Role of Pelvic Stability Evaluation in the Era of Computed Tomographic Scanning. Medicine (Baltimore). 2016;95(16):e3421.

21. Schicho A, Schmidt SA, Seeber K, Olivier A, Richter PH, Gebhard F. Pelvic X-ray misses out on detecting sacral fractures in the elderly - Importance of CT imaging in blunt pelvic trauma. Injury. 2016;47(3):707-10.

22. Kessel B, Sevi R, Jeroukhimov I, Kalganov A, Khashan $T$, Ashkenazi I, et al. Is routine portable pelvic $X$-ray in stable multiple trauma patients always justified in a high technology era? Injury. 2007;38(5):559-63.

23. Al Balushi AA, Malik KA. Role of pelvic X-ray in blunt trauma patients -- $A$ university hospital experience in Oman. J Pak Med Assoc. 2015;65(8):910-2.

24. Paydar S, Ghaffarpasand F, Foroughi M, Saberi A, Dehghankhalili $M$, Abbasi $H$, et al. Role of routine pelvic radiography in initial evaluation of stable, high-energy, blunt trauma patients. Emerg Med J. 2013;30(9):724-7.

25. Obaid AK, Barleben A, Porral D, Lush S, Cinat M. Utility of plain film pelvic radiographs in blunt trauma patients in the emergency department. Am Surg. 2006;72(10):951-4. 
26. Dechert TA, Duane TM, Frykberg BP, Aboutanos MB, Malhotra AK, Ivatury RR. Elderly patients with pelvic fracture: interventions and outcomes. Am Surg. 2009;75(4):291-5.
Received in: 22/05/2020

Accepted for publication: 29/06/2020

Conflict of interest: no.

Funding source: none.

\section{Mailing address:}

Pedro de Souza Lucarelli-Antunes

E-mail: lucarelli_2007@yahoo.com.br

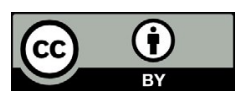

